\title{
The siRNA silencing of DcR3 expression induces Fas ligand-mediated apoptosis in HepG2 cells
}

\author{
TUANJIE ZHAO, YINGCHEN XU, SHULIN REN, CHAOJIE LIANG, XIAONA ZHOU and JIXIANG WU \\ Department of General Surgery, Beijing Tongren Hospital, Capital Medical University, Beijing 100730, P.R. China
}

Received October 12, 2016; Accepted February 8, 2018

DOI: $10.3892 /$ etm.2018.5964

\begin{abstract}
Dysfunctional Fas ligand (FasL) may inhibit the apoptosis of tumor cells. FasL contains two receptors, Fas and Decoy Receptor 3 (DcR3). DcR3 competitively binds to FasL over Fas, resulting in the inhibition of FasL-mediated apoptosis. Therefore, it was suggested that the downregulation of DcR3 expression enhances FasL-mediated apoptosis. In the current study, the expression of DcR3 was silenced in liver cancer HepG2 cells in order to study the effect of FasL on HepG2 cell activity and invasiveness. DcR3 siRNA knockdown HepG2 cells (KD), DcR3 blank plasmid control HepG2 cells and wild-type HepG2 cells (WT) were treated with FasL $(10 \mathrm{ng} / \mathrm{ml})$. Flow cytometry was used to detect changes in the cell cycle and apoptosis. MTS, clonogenic, wound healing and Transwell assays were performed to examine changes in cell activity, proliferation, migration and invasiveness. Reverse transcription polymerase chain reaction and western blot analysis were performed to measure the expression of DcR3, matrix metallopeptidase 9 (MMP9), vascular endothelial growth factor (VEGF)-C and VEGF-D. The results demonstrated that, compared with WT cells, the proportion of KD cells in the G2/M phase decreased following treatment with FasL. KD cells were more sensitive to FasL-induced apoptosis. Following treatment with FasL, the activity and proliferation, migration and invasion of KD cells were reduced, and the expression of MMP9, VEGF-C and VEGF-D decreased. Furthermore, it was demonstrated that DcR3 is involved in the proliferation and invasion of HepG 2 cells, and this mechanism may be associated with the regulatory effect of the expression of MMP9, VEGF-C and VEGF-D; however, the exact mechanism of action remains unclear. FollowingDcR3 silencing, FasL-mediated apoptosis increased in HepG2 cells. Therefore, DcR3 combined with FasL may be a potential target for the treatment of liver cancer.
\end{abstract}

Correspondence to: Professor Jixiang Wu, Department of General Surgery, Beijing Tongren Hospital, Capital Medical University, 1 Dongjiaominxiang Street, Beijing 100730, P.R. China

E-mail:wjx95@hotmail.com

Key words: decoy receptor 3, Fas ligand, HepG2, small interfering RNA, apoptosis

\section{Introduction}

Liver cancer is a growing problem in less developed countries and, according to the GLOBOCAN 2012 (1), it is the second most common cause of cancer-associated mortality worldwide. The disease burden of liver cancer is increasing markedly across the world (2). If liver cancer is diagnosed at an early stage, patients are able to undergo effective treatment via liver resection, transplantation or ablation, and the 5-year survival rate of such patients is $>50 \%$ (3). However, the prognosis of patients with advanced liver cancer is very poor and the 5-year survival rate of such patients is <5\% (4).

Hepatoblastoma is a highly malignant liver cancer that occurs most commonly in children (5). The 5-year overall survival rate of patients with stage IV hepatoblastoma is $\sim 40 \%$ (6). The standard method of treating patients with hepatoblastoma is surgery combined with high dose, non-targeted chemotherapy; however, such chemotherapy induces severe side effects in patients, including ototoxicity and cardiotoxicity $(7,8)$. Therefore, novel therapeutic strategies to treat patients with hepatoblastoma are required.

Due to advances in molecular biology, a number of tumor-associated genes have been identified, including CTNNB1 and $\beta$-Catenin in hepatoblastoma (9). Current studies focusing on gene therapy aim to develop molecular biological methods to inhibit the in vivo expression of such genes in order to treat patients with cancer. Studies investigating methods of treating cancer via gene therapy tend to focus on genes that induce the apoptosis of cancer cells (10-12).

The abnormal activation of apoptosis pathways may induce the onset and progression of numerous diseases, including different types of cancer. The Fas/Fas ligand (FasL) system is one such important apoptotic pathway (12). Ogasawara et al (13) demonstrated that the liver is more sensitive to Fas-mediated apoptosis compared with other organs. FasL, a type II membrane protein, belongs to the tumor necrosis factor (TNF) superfamily (14). Fas, which is a member of the TNF receptor (TNFR) family, is widely expressed in normal cells, including liver, kidney and heart cells, and binds to FasL (15). Fas is involved in transferring the apoptotic signal, resulting in cell apoptosis (16) and the Fas/FasL system is a key physiological regulator of programmed cell death (17). It has been demonstrated that resistance to apoptosis due to loss of Fas function may serve an important role in the pathogenesis of several malignancies (18). 
FasL contains two receptors, Fas and decoy receptor 3 (DcR3). DcR3, initially identified by Pitti et al (19), does not contain a death domain and so cannot transfer apoptotic signals (20). DcR3 competitively binds to FasL over Fas, thus inhibiting FasL-induced apoptosis (21) and may contribute to tumor growth in this manner (22). Furthermore, DcR3 binds to FasL and inhibits FasL-induced apoptosis. DcR3 is highly expressed in many malignant tumors, including liver cancer (23-25). It has been demonstrated that the expression of DcR3 mRNA is $60.4 \%$ in liver cancer tissues; however, it is not expressed in the adjacent normal tissues. Furthermore, DcR3 expression is associated with tumor size, clinical stage, tumor invasion and metastasis (23). Yu et al (26) demonstrated that decreasing DcR3 expression in SW480 colon cancer cells inhibited cell growth and metastatic ability, induced apoptosis and altered the cell cycle profile of these cells. However the exact molecular mechanism underlying the oncogenic property of DcR3 in liver cancer remains unclear.

Our previous study by the current study transfected human liver cancer HepG2 cells with lentivirus-based short hairpin RNA vector targeting DcR3 stably and indicated the that loss of DcR3 impaired the growth and invasive ability of HepG2 (27). The present study also used the HepG2 cell line, which was established in 1979 and mistakenly reported as a hepatocellular carcinoma cell line (28). However, in 2009, it was demonstrated that HepG2 cells originated from hepatoblastoma, not hepatocellular carcinoma (29). The results of the current study are relevant to hepatoblastoma and liver cancer in general, however, they may not be useful regarding hepatocellular carcinoma.

Therefore, in the current study, HepG2 cells that had undergone DcR3 knockdown by small interfering (si)RNA knockdown were treated with FasL to assess the effect of FasL on HepG2 cell activity and invasive capabilities.

\section{Materials and methods}

Reagents. Reagents and kits included: Dulbecco's modified Eagle's medium (DMEM) and fetal bovine serum (FBS; Gibco; Thermo Fisher Scientific, Inc., Waltham, MA, USA), TRIzol (Invitrogen; Thermo Fisher Scientific, Inc.), a prime Script RT reagent kit and SYBR Premix Ex Taq (Takara Bio, Inc., Otsu, Japan), Transwell inserts (Axygen; Corning Inc., Corning, NY, USA), Matrigel (BD Biosciences, San Jose, CA, USA), human recombinant FasL (R\&D Systems, Inc., Minneapolis, MN, USA), rabbit anti-human GAPDH polyclonal antibody (cat. no. 5714; Cell Signaling Technology, Inc., Danvers, MA, USA) and rabbit anti-human matrix metallopeptidase 9 (MMP9) polyclonal antibody (cat. no. ab38898), rabbit anti-human vascular endothelial growth factor C (VEGF-C) monoclonal antibody (cat. no. ab191274), rabbit anti-human VEGF-D polyclonal antibody (cat. no. ab155288) and horseradish peroxidase (HRP)-conjugated goat anti-rabbit secondary antibodies (cat. no. ab205718) (all Abcam, Cambridge, UK).

Cell culture. Hepatoblastoma HepG2 cells were purchased from the Cell Bank at Peking Union Medical College Cancer Hospital (Beijing, China). Cells were cultured at $37^{\circ} \mathrm{C}$, in $5 \% \mathrm{CO}_{2}$ and saturated humidity in DMEM with $10 \% \mathrm{FBS}$, $100 \mathrm{U} / \mathrm{ml}$ ampicillin, and $100 \mu \mathrm{g} / \mathrm{ml}$ streptomycin.
Cell transfection. In our previous study (27), HepG2 cells were successfully transfected with target lentivirus Lv-DcR3-EGFP-shRNA [the sequence with a stem-loop structure was CGCTGGTTTCTGCTTGGAGCA-CTC GAG-TGCTCCAAGCAGAAACCAGCG (Beijing TransGen Biotech, Co., Ltd., Beijing, China)] and blank lentivirus Lv-NC-EGFP-shRNA(Beijing TransGen Biotech, Co., Ltd.) using the Lipofectamine 2000 reagent (Invitrogen; Thermo Fisher Scientific, Inc.). The ratio of plasmid DNA $(\mu \mathrm{g}) /$ Lipofectamine 2000 reagent $(\mu \mathrm{l})$ was 1:3.5, and DcR3 siRNA knockdown in HepG2 cells (KD) was achieved and DcR3 blank plasmid negative control HepG2 cells were utilized (negative control, NC). The interval between transfection and subsequent experimentation was 4 weeks. Wild-type HepG2 cells (WT) were used as a normal control.

Detection of apoptosis. HepG2 WT cells and KD cells were seeded into 6 -well plates at $5 \times 10^{5}$ cells/well. Following $24 \mathrm{~h}$ incubation, KD cells were incubated with dimethyl sulfoxide (DMSO) containing FasL (10 ng/ml; KD + Fas L). KD and WT cells incubated with DMSO alone acted as controls. Following $48 \mathrm{~h}$ incubation, cells were digested with trypsin and centrifuged at $1,000 \mathrm{x}$ g for $5 \mathrm{~min}$ at room temperature. Cells were then washed with PBS and centrifuged at $1,000 \mathrm{xg}$ for $5 \mathrm{~min}$ at room temperature. Cells were resuspended in PBS, $10 \times 10^{4}$ cells were transferred into a centrifuge tube and centrifuged at $1,000 \mathrm{x} \mathrm{g}$ for $5 \mathrm{~min}$ at room temperature. Apoptosis was detected using an Annexin V-fluorescein isothiocyanate (FITC) cell apoptosis assay kit (Beyotime Institute of Biotechnology, Haimen, China). Cells were resuspended in $195 \mu \mathrm{l}$ Annexin V-FITC; then $5 \mu \mathrm{l}$ Annexin V-FITC was added and mixed well. Following $10 \mathrm{~min}$ incubation at $20-25^{\circ} \mathrm{C}$, cells were centrifuged at $1,000 \mathrm{x} \mathrm{g}$ for $5 \mathrm{~min}$ and the supernatant was discarded. Cells were then resuspended in $190 \mu \mathrm{l}$ Annexin V-FITC and $10 \mu \mathrm{l}$ propidium iodide (PI) was added and mixed well. PI staining was performed at room temperature for $20 \mathrm{~min}$ in the dark. A flow cytometer was used to assess the results; cells stained with Annexin V-FITC exhibited green fluorescence and those stained with PI exhibited red fluorescence. Flow cytometry data were analyzed using CellQuest Pro 5.10 (BD Biosciences, Franklin Lakes, NJ, USA). The cells were properly gated and a dual-parameter dot plot of FL1-H (x-axis; Annexin V fluorescence) vs. FL2-H (y-axis; PI fluorescence) was demonstrated to be logarithmic in fluorescence intensity.

Cell cycle analysis. HepG2 WT cells and KD cells were seeded into 6 -well platesat $5 \times 10^{5}$ cells/well. Following $24 \mathrm{~h}$ incubation, $\mathrm{KD}+$ Fas L cells were incubated with DMSO containingn Fas (10 ng/ml). KD and WT cells incubated with DMSO alone acted as controls. Following 48 h, cells were washed with PBS and digested with trypsin. Cells were then transferred to a centrifuge tube and centrifuged at $1,000 \mathrm{x}$ g for $5 \mathrm{~min}$ at room temperature; the supernatant was then discarded. The cells were resuspended with $0.9 \% \mathrm{NaCl}$ and then the supernatant was discarded. Subsequently, cells were fixed with $1 \mathrm{ml} 75 \%$ ethanol overnight at $-20^{\circ} \mathrm{C}$. Following fixation, cells were centrifuged at $1,000 \times \mathrm{g}$ at $4^{\circ} \mathrm{C}$ for $5 \mathrm{~min}$ and the supernatant was discarded. The cells were washed twice with $\mathrm{NaCl} 0.9 \%$ with $1 \%$ bovine serum albumin (Sigma-Aldrich; 
Merck KGaA, Darmstadt, Germany) added. Following the addition of $50 \mu \mathrm{l}$ RNAse (Sigma-Aldrich; Merck KGaA) and $50 \mu \mathrm{l}$ PI for $20 \mathrm{~min}$, cells were left in the dark at $4^{\circ} \mathrm{C}$. Cells were mixed gently on ice in the dark and then flow cytometry was performed. Flow cytometry data were analysed using Cell Quest Pro 5.10(BD Biosciences). The DNA content (x-axis, PI fluorescence) vs. counts (y-axis) was plotted as a histogram.

MTS cell proliferation assay. Cells in the WT, NC, and KD groups were seeded into 96-well plates at 2,000 cells/well. Following $24 \mathrm{~h}$ incubation, each group of cells (WT, NC and KD) were incubated either with DMEM containing FasL $(10 \mathrm{ng} / \mathrm{ml})$ or DMEM alone. Cells were incubated at $37^{\circ} \mathrm{C}$ in $5 \% \mathrm{CO}_{2}$ for 8 days. Subsequently, $20 \mu \mathrm{l}$ CellTiter $96^{\circledR}$ AQueous One Solution Reagent (Promega Corporation, Madison, WI, USA) was added to each well and incubated at $37^{\circ} \mathrm{C}$ for $3 \mathrm{~h}$ in $5 \% \mathrm{CO}_{2}$. Optical density was measured at $490 \mathrm{~nm}$ everyday using Plate reader spectrophotometer (Bio-Rad Laboratories, Inc., Hercules, CA, USA).

Clonogenic assay. For each experimental group (WT, NC and KD cells), 800 cells/well were seeded into a 6-well plate. Following $24 \mathrm{~h}$ incubation, each group of cells (WT, NC and KD) were incubated either with DMEM containing FasL (10 ng/ml) or DMEM alone. When clones became visible, the supernatant was discarded and clones were washed with PBS for 3 times. Cells were fixed in $4 \%$ paraformaldehyde for $15 \mathrm{~min}$ at room temperature. Following three washes in PBS, cells were stained with $1 \%$ crystal violet solution at $37^{\circ} \mathrm{C}$ for 10-30 min. Plates were then air-dried and the numbers of clones were calculated. The colony formation rate (\%) was calculated using the following formula:(number of clones/number of inoculated cells) x100.

Wound healing assay. WT, NC and KD cells were seeded at $1 \times 10^{5} / \mathrm{ml}$ into 6 -well plates and cultured until cells grew to filled the plates. A $200 \mu$ pipet tip was used to evenly scratch across the well (at intervals of 0.5-1.0 cm) 5 times, with the tip kept vertical. Removed cells were washed with PBS (3 times) and each group of cells (WT, NC and KD) was incubated either with DMEM containing FasL (10 ng/ml) or DMEM alone. Plates were incubated at $37^{\circ} \mathrm{C}$ with $5 \% \mathrm{CO}_{2}$ for $48 \mathrm{~h}$, and samples were photographed at 0,24 and $48 \mathrm{~h}$.

Cell invasion assay. The apical side of the membrane of the Transwell inserts was coated with $50 \mathrm{mg} / \mathrm{l}$ Matrigel at a dilution of $1: 8$ and was then air-dried at $4^{\circ} \mathrm{C}$. A total of $3 \times 10^{3}$ cells from each group in $200 \mu \mathrm{l}$ serum-free medium was added to the upper chamber of the Transwell assay. DMEM containing FasL (10 ng/ml) and 1\% FBS (Gibco; Thermo Fisher Scientific, Inc.) was added to the chamber below the insert, DMEM without FasL was used as the control. Following incubation at $37^{\circ} \mathrm{C}$ for $24 \mathrm{~h}$, the inserts were taken out and washed twice with PBS. A cotton swab was used to remove the membrane matrix and the cells on the apical side of the insert. Cells on the basal side of the insert were fixed using formaldehyde for $30 \mathrm{~min}$ at room temperature and subsequently stained with crystal violet for $20 \mathrm{~min}$ at room temperature. Cells were washed with water 3-5 times. The mean cell count of five randomly selected microscopic fields using a light microscope was used for each sample. For each group, 3 repeats were carried out. The relative invasion rate (\%) was calculated using the following formula: (The number of invasive cells in the treated sample/the number of invasive cells in the control) $\times 100 \%$.

Reverse transcription-quantitative polymerase chain reaction $(R T-q P C R)$. WT, NC and KD cells were inoculated in 6-well plates at $5 \times 10^{5}$ cells/well. Following $24 \mathrm{~h}$ incubation, each group of cells (WT, NC and KD) were incubated either with DMEM containing FasL (10 ng/ml) or DMEM alone. After $48 \mathrm{~h}$, total RNA was extracted from each group using TRIzol and reverse transcribed into cDNA using the Prime Script RT reagent kit following the manufacturers' protocol. qPCR was performed using the SYBR Premix Ex Taq (Takara Bio, Inc.). The primer sequences used were as follows: DcR3, forward, 5'-GGTACCAGGAGCTGAGGAGTGT'-3 and reverse, 5'-CCTTGGTGTCGGACCCCA-3'; MMP 9, forward, 5'-TGT ACCGCTATGGTTACACTCG-3' and reverse, 5'-GGCAGG GACAGTTGCTTCT-3'; VEGF-C, forward, 5'-GGCTGG CAACATAACAGAGAA-3' and reverse, 5'-CCCCACATC TATACACACCTCC-3'; VEGF-D, forward, 5'-TCCCATCGG TCCACTAGGTTT-3' and reverse, 5'-AGGGCTGCACTG AGTTCTTTG-3'; GAPDH (the internal control), forward, 5'-GTCGGAGTCAACGGATTTGG-3' and reverse, 5'-AAA AGCAGCCCTGGTGACC-3'.

The qPCR conditions were: Initial denaturation at $94^{\circ} \mathrm{C}$ $2 \mathrm{~min}, 30$ cycles of denaturation at $94^{\circ} \mathrm{C}$ for $30 \mathrm{sec}$, annealing at $55^{\circ} \mathrm{C}$ for $30 \mathrm{sec}$ and elongation at $72^{\circ} \mathrm{C}$ for $60 \mathrm{sec}$; and final extension at $72^{\circ} \mathrm{C}$ for $10 \mathrm{~min}$. Relative mRNA expression was calculated using the $2^{-\Delta \Delta \mathrm{Cq}}$ method (30).

Western blot analysis. Each group of cells was washed in PBS at $4^{\circ} \mathrm{C}$ and then radioimmuniprecipitation assay lysis buffer (Nanjing KeyGen Biotech Co., Ltd., Nanjing, China) containing phenylmethylsulfonyl fluoride was added for $5 \mathrm{~min}$. Lysates were centrifuged at $12,000 \mathrm{x}$ g for $5 \mathrm{~min}$ at $4^{\circ} \mathrm{C}$. The protein concentration in the supernatant was quantified using a BCA kit. Protein samples $(30 \mu \mathrm{g})$ were separated using $12 \%$ SDS-PAGE and then transferred to nitrocellulose membranes. Following blocking with 5\% skimmed milk for $1 \mathrm{~h}$ at room temperature, rabbit anti-human MMP9 polyclonal antibody $(1: 1,000)$, rabbit anti-human VEGF-C polyclonal antibody $(1: 1,000)$, rabbit anti-human VEGF-D monoclonal antibody $(1: 1,000)$, rabbit anti-human GAPDH antibody $(1: 5,000)$ were added and membranes were incubated at $4^{\circ} \mathrm{C}$ overnight. Following washing with TBST, horseradish peroxidase-labeled goat anti-rabbit secondary antibody $(1: 5,000)$ was added and incubated at room temperature for $1 \mathrm{~h}$. Enhanced chemiluminescent agent (EMD Millipore, Billerica, MA, USA) was added following washing with TBST. A Bio-Rad gel imaging system (BioradGelDoc XR; Bio-Rad Laboratories, Inc.) was used to capture the images, and GAPDH was used as the internal control for the analysis of DcR3, MMP9, VEGF-C, and VEGF-D.

Statistical analysis. Values are expressed as the mean \pm standard deviation. All statistical analyses were performed using GraphPad Prism software version 6.0 (GraphPad Software, Inc., La Jolla, CA, USA). The statistical significance among groups was determined by two-tailed 
A

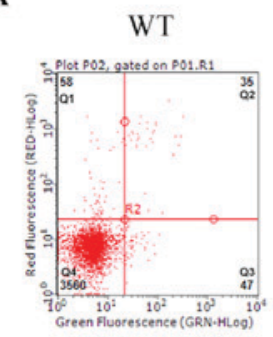

KD

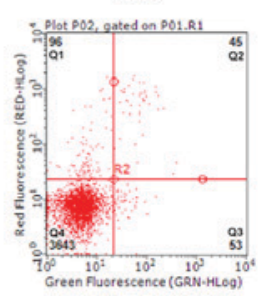

KD+FasL

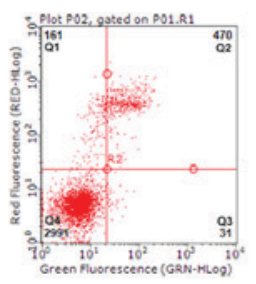

C

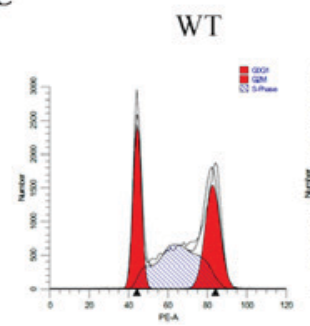

KD

$\mathrm{KD}+\mathrm{FasL}$

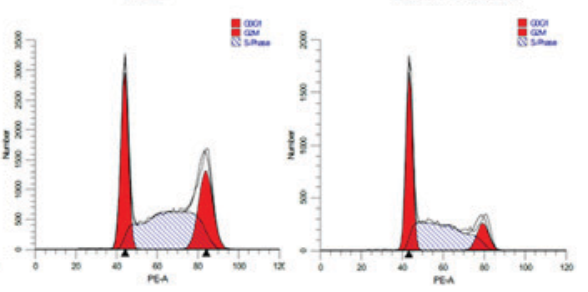

D

B

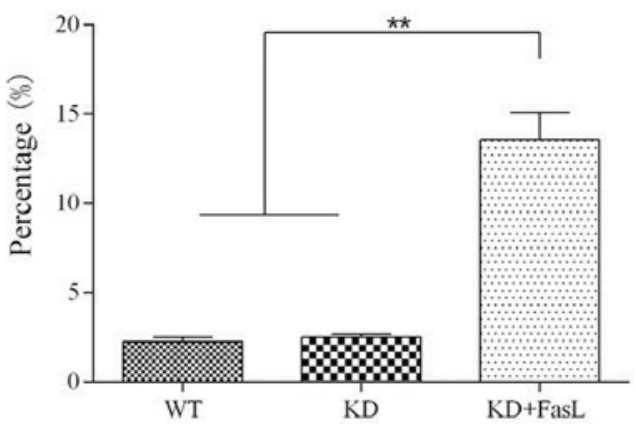

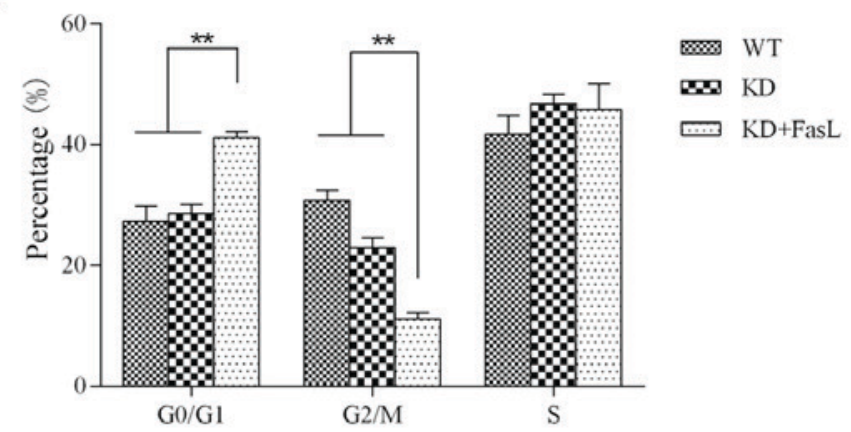

Figure 1. Effects of FasL on the apoptosis and cell cycle of various groups of cells. (A) Flow cytometry presenting the apoptosis of cells in each group; (B) the proportion of apoptotic cells in each group; (C) cell cycle analysis; (D) quantification of cell cycle analysis. ${ }^{* *} \mathrm{P}<0.01$. FasL, Fas ligand; WT, wild-type HepG2 cells; KD, DcR3 knockdown HepG2 cells; NC, negative control HepG2 cells; DcR3, Fas and decoy receptor 3.

analysis of variance followed by Dunnett's multiple comparisons test. $\mathrm{P}<0.05$ was considered to indicate a significant difference. All experiments were performed in triplicate and repeated at least three times.

\section{Results}

Following DcR3 knockdown, HepG2 cells became more sensitive to FasL-induced apoptosis. Flow cytometric analysis indicated that, following treatment with FasL, the proportion of KD cells exhibiting signs of early apoptosis was $12.29 \pm 1.12 \%$, which was significantly higher than that of the KD $(1.12 \pm 0.10 \%)$ and WT $(0.99 \pm 0.10 \%)$ groups $(\mathrm{P}<0.01$; Fig. 1A and B).

Cell cycle analysis by flow cytometry indicated that the proportion of cells in the KD + FasL group in the $G_{0} / G_{1}$ phase $(41.12 \pm 1.02 \%)$ was significantly greater than that of the KD $(28.59 \pm 1.51 \%)$ and WT $(27.34 \pm 2.52 \%)$ groups $(\mathrm{P}<0.01$; Fig. $1 \mathrm{C}$ and D). Furthermore, the proportion of cells in the $\mathrm{G} 2 / \mathrm{M}$ phase in the KD + FasL group $(11.11 \pm 1.10 \%)$ was significantly lower than that of the KD $(22.98 \pm 1.71 \%)$ and the WT $(30.84 \pm 1.61 \%)$ groups $(\mathrm{P}<0.01)$.

Following DcR3 knockdown, FasL decreases the proliferation, migration and invasion of HepG2 cells. The results of the MTS assay demonstrated that, compared with the WT and NC groups, the proliferation rates of cells in the KD, $\mathrm{WT}+\mathrm{FasL}, \mathrm{NC}+\mathrm{FasL}$ and $\mathrm{WT}+$ FasL groups from day 3 onwards were significantly decreased compared with the WT group $(\mathrm{P}<0.05$ or $\mathrm{P}<0.01$; Fig. $2 \mathrm{~A})$. The proliferation rate of cells in the KD + FasL group was significantly lower. These results indicate that FasL decreases cell proliferation and that this impact is enhanced following DcR3 knockdown.
The results of the wound healing assay indicated that FasL reduced cell migration, with the most significant decrease identified in the KD + FasL group. Cell migration was significantly decreased in the KD + FasL group compared with all other groups at $48 \mathrm{~h}(\mathrm{P}<0.01$; Fig. $2 \mathrm{~B}$ and $\mathrm{C})$.

The results of the clonogenic assay demonstrated that compared with the WT group, the number of clones in the $\mathrm{KD}, \mathrm{WT}+$ FasL, NC + FasL and KD + FasL groups all decreased (Fig. 3A and B). The greatest decrease was found in the KD + FasL group; the number of clones was significantly decreased in this group compared with all other groups, $(\mathrm{P}<0.01)$. These results indicate following DcR3 silencing, treatment with FasL further decreases HepG2 cell proliferation.

Furthermore, the results of the Transwell cell migration assay demonstrated that the number of cells in the KD + FasL group passing through the Matrigel membrane was significantly decreased compared with all other groups $(\mathrm{P}<0.01$; Fig. 3C and D). These results suggest that FasL decreases the invasiveness of HepG2 cells.

Following DcR3 knockdown, the expression of VEGF-C, $V E G F-D$ and MMP9 decreases following treatment of Hep 2 cells with FasL. The results of RT-qPCR demonstrated that, compared with the other groups, the expression of VEGF-C, VEGF-D and MMP 9 mRNA in the KD + FasL group was significantly decreased $(\mathrm{P}<0.01$; Fig. 4). The same trend was observed regarding the expression of VEGF-C, VEGF-D and MMP9 protein following western blotting.

\section{Discussion}

The Fas/FasL system is an apoptotic pathway that serves an important role in maintaining immune homeostasis (31) and tumorigenesis (32). Under normal circumstances, Fas is highly 

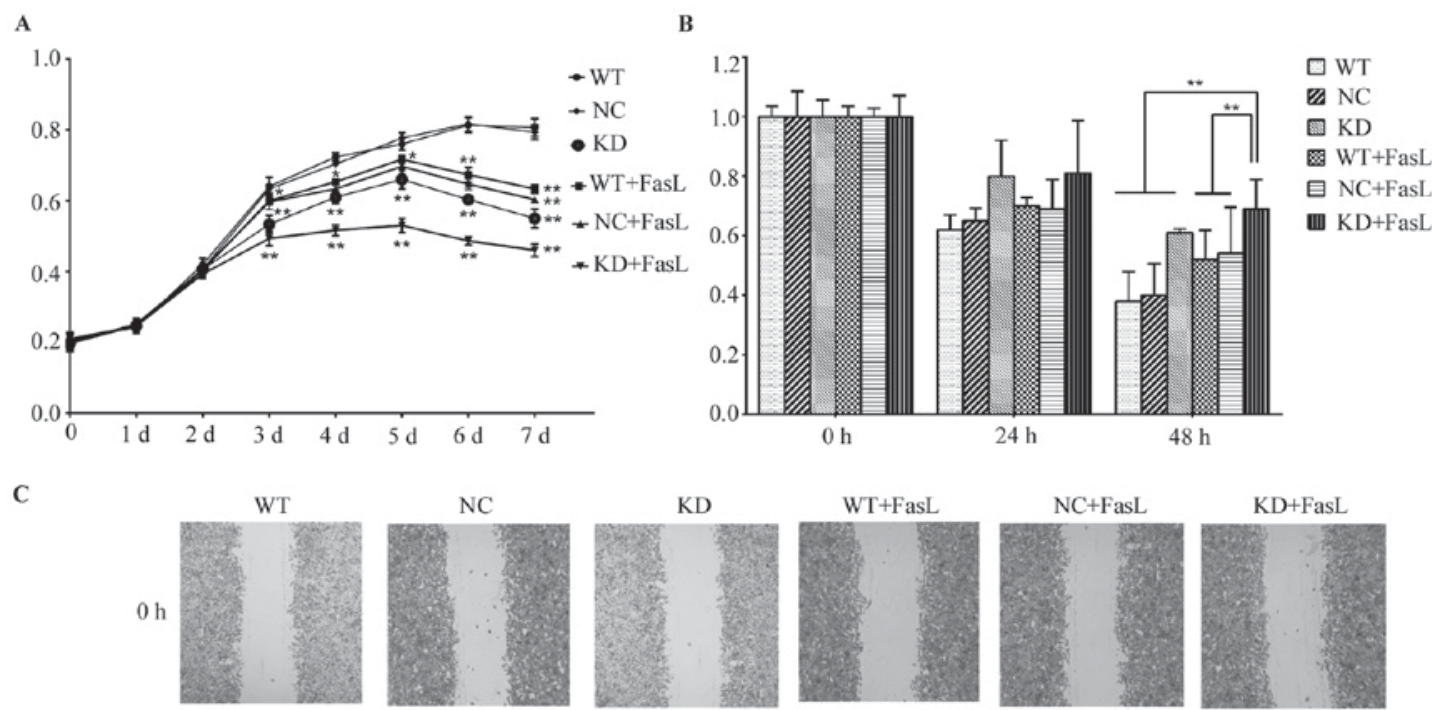

NC

$\mathrm{KD}$
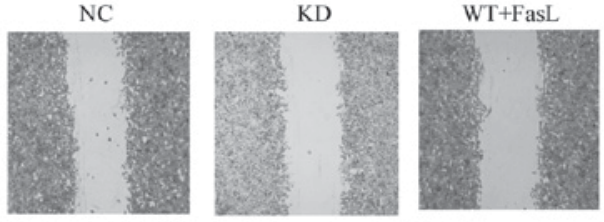

$\mathrm{NC}+\mathrm{FasL}$

KD+FasL
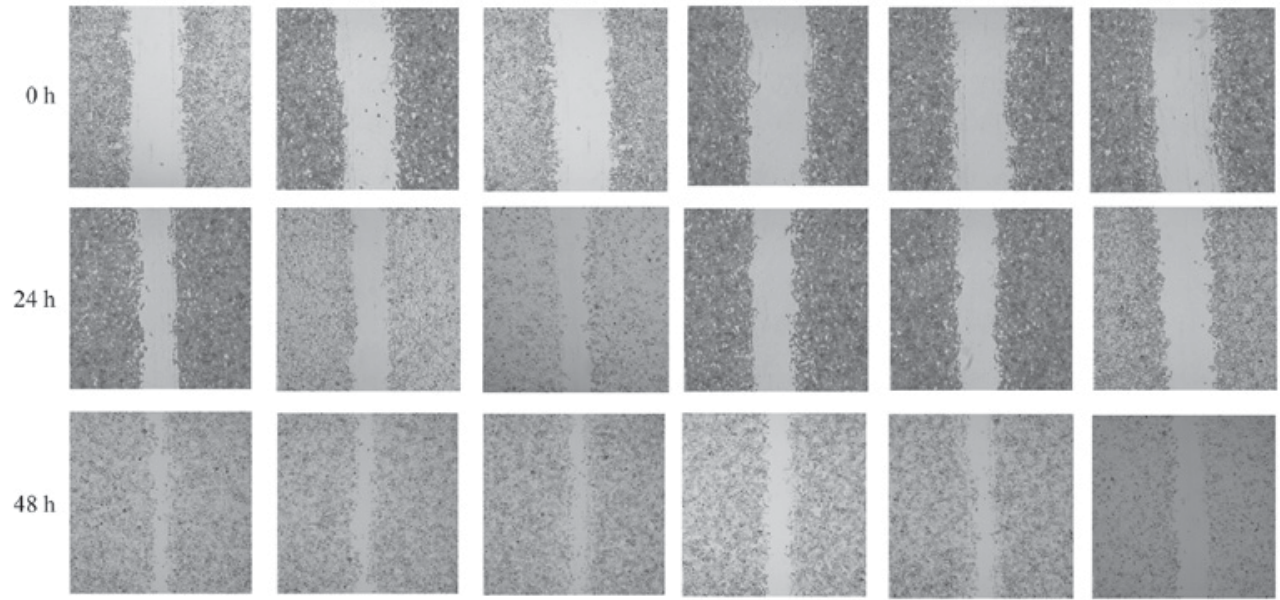

Figure 2. Effects of FasL on the activity and migration of HepG2 cells. (A) The results of the MTS assay. From Day 3, the OD values of the KD, WT + FasL, $\mathrm{NC}+$ FasL and KD + FasL groups were lower than the WT group, respectively. The OD value in the KD + FasL group was the lowest. (B and C) The results of the wound healing assay indicated that following the addition of FasL, cell migration was reduced in all treatment groups; the decrease in the KD cells was the most significant. "P<0.05, ${ }^{* *} \mathrm{P}<0.01$. OD, optical density; FasL, Fas ligand; KD, DcR3 knockdown HepG2 cells; WT, wild-type HepG2 cells; NC, negative control HepG2 cells; DcR3, Fas and decoy receptor 3.

A

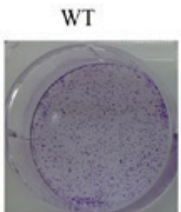

WT + FasL

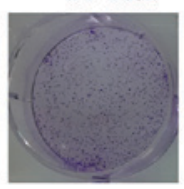

C

WT

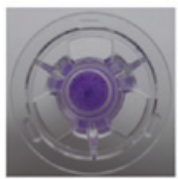

WT+FasL

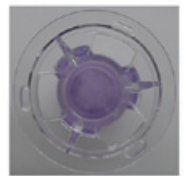

NC

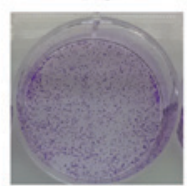

$\mathrm{NC}+\mathrm{FasL}$

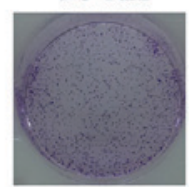

$\mathrm{NC}$

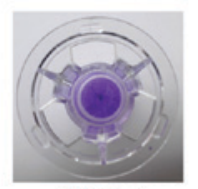

$\mathrm{NC}+\mathrm{FasL}$

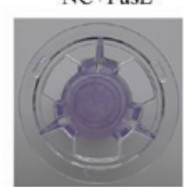

KD

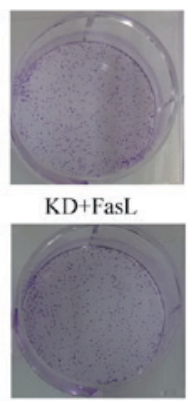

KD

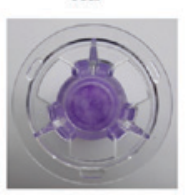

KD+FasL

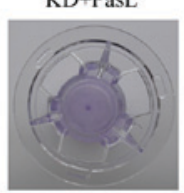

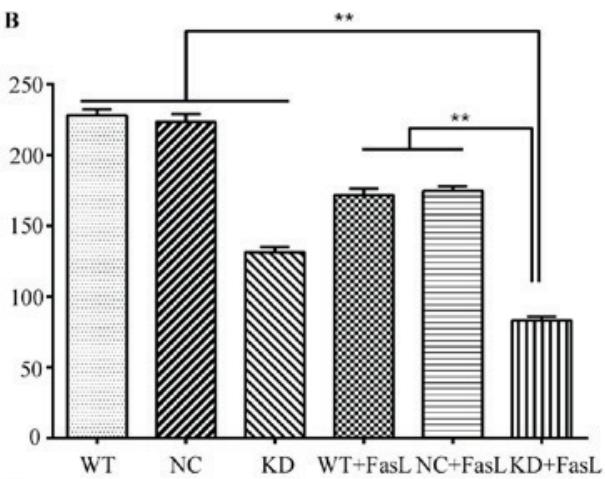

D

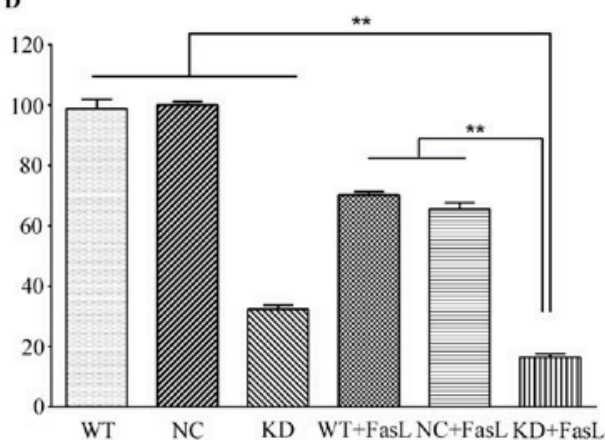

Figure 3. Effects of FasL on the proliferation and invasiveness of HepG2 cells. (A and B) Results of the clonogenic assay demonstrated that following treatment with FasL, the clonogenic ability of the KD group was decreased compared with other groups. ${ }^{* *} \mathrm{P}<0.01$. (C and D) The results of the Transwell cell migration assay indicated that the invasive ability of the KD cells decreased significantly following addition of FasL. ${ }^{* * *} \mathrm{P}<0.01$. FasL, Fas ligand; WT, wild-type HepG2 cells; KD, DcR3 knockdown HepG2 cells; NC, negative control HepG2 cells; DcR3, Fas and decoy receptor 3. 
A

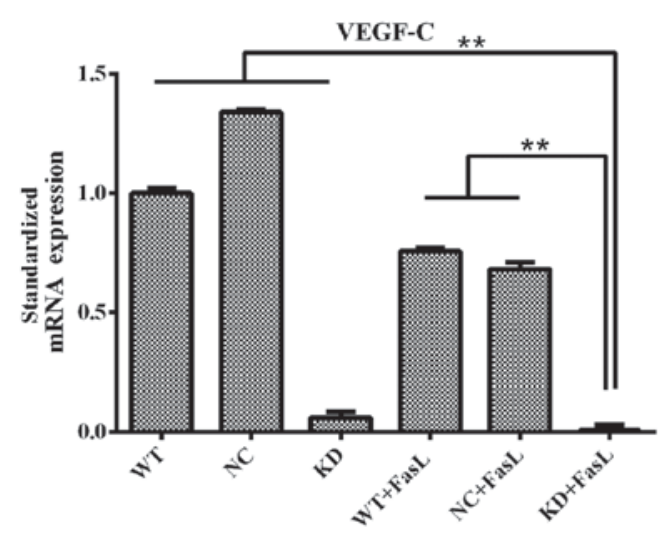

C

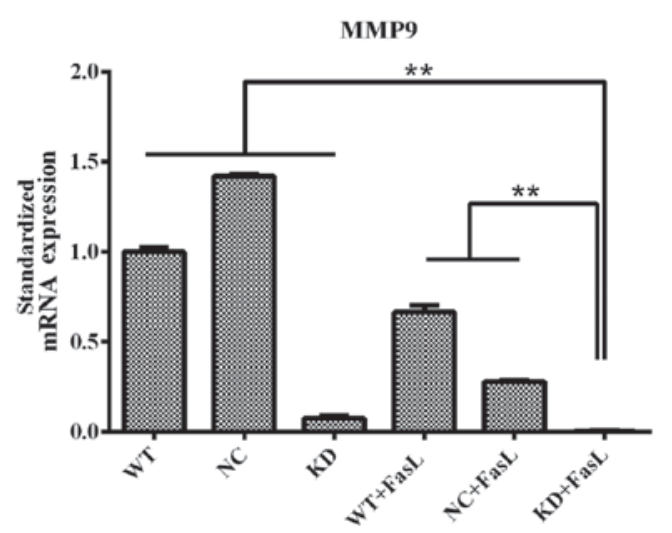

B
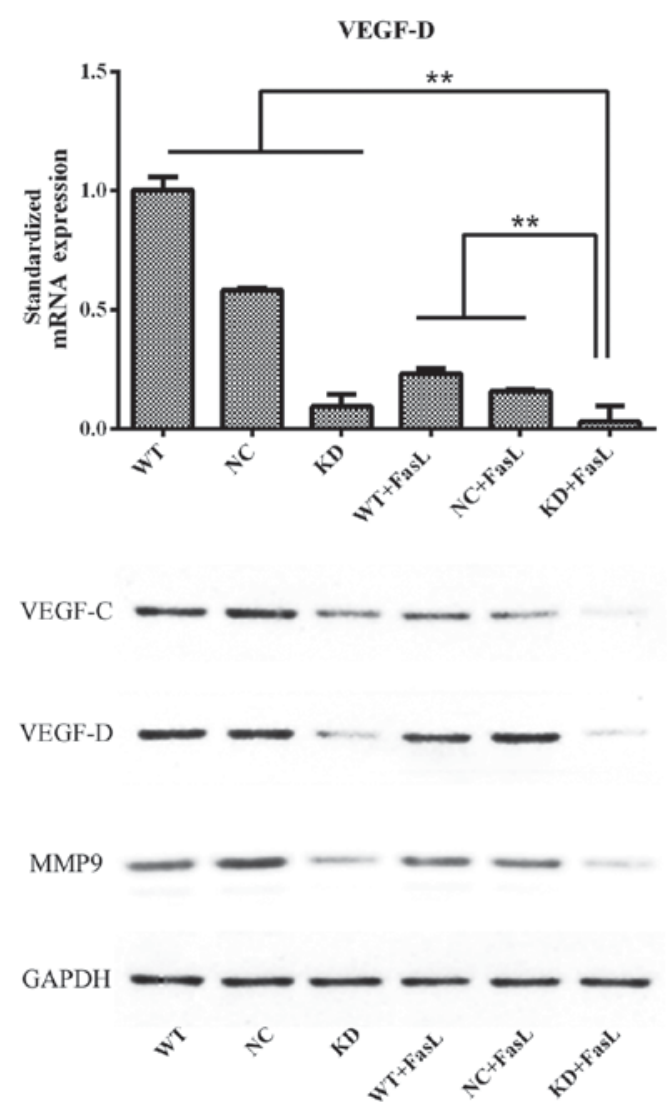

Figure 4. Changes in the expression of (A) VEGF-C, (B) VEGF-D and (C) MMP9 mRNA in HepG2 cells following exposure to FasL. ** $<0.01$. (D) Results of western blotting presenting the expression of VEGF-C, VEGF-D and MMP9 protein in each of the groups. MMP9, matrix metallopeptidase 9, VEGF-C, vascular endothelial growth factor C, VEGF-D, vascular endothelial growth factor D; FasL, Fas ligand; WT, wild-type HepG2 cells; KD, DcR3 knockdown HepG2 cells; NC, negative control HepG2 cells; DcR3, Fas and decoy receptor 3.

expressed in various cells and the development of tumors is often associated with a lack of Fas expression or function, and the increased expression of FasL in tumor cells (33). It has been established that Fas/FasL not only induces apoptosis, but also triggers multiple signaling pathways to inhibit apoptosis; furthermore, its abnormal expression is closely associated with tumorigenesis (34). It may stimulate tumor cell proliferation and promote tumor cell migration and invasion via the nuclear factor $-\kappa \mathrm{B}$, mitogen-activated protein kinase and phosphatidylinositol 3-kinase pathways (35). FasL contains two receptors, Fas and DcR3. DcR3 competitively binds to FasL over Fas, thereby inhibiting FasL-induced apoptosis.

The DcR3 gene was identified in 1998 by Pitti et al (19) and is closely associated with tumorigenesis. In the majority of tissues, the expression of DcR3 is negligible; however, it is highly expressed in many different types of cancer, including esophageal (19), gastric (19), colon (19), rectal (19), pancreatic (23), liver (23-25), lung (19,23), kidney (36), breast (23), ovarian (37) and skin cancer (38).

Connolly et al (21) intravenously injected FasL to Fas+ mice and demonstrated that the mice succumbed to acute fatal fulminant hepatic necrosis in $\leq 2 \mathrm{~h}$; however, this did not occur in mice pre-treated with DcR3. It was therefore hypothesized that DcR3 reduces Fas-mediated liver cell necrosis. Hayashi et al (39) demonstrated that downregulating DcR3 expression using siRNA may increase Fas-mediated apoptosis and using TNF- $\alpha$ to increase the expression of DcR3 could inhibit Fas-mediated apoptosis in rheumatoid arthritis synovial fibroblasts. Li et al (40) indicated that DcR3 expression in the human gastric cancer BGC823 and breast cancer MCF-7 cell lines were 35.3 and $21.6 \%$, whereas the apoptosis induced by FasL was 15.6 and 58.2\%, respectively. Therefore, it was suggested that FasL-mediated apoptosis was directly associated with levels of DcR3 expression (40). The results of the current study demonstrated that FasL-induced apoptosis was increased when DcR3 in HepG2 cells was silenced, which is in accordance with the aforementioned experimental results. Furthermore, FasL significantly decreased the proliferation and invasiveness of KD cells. These results indicate that FasL may impair the proliferation and invasiveness of HepG 2 cells more effectively when DcR3 expression is decreased.

Tumor invasion and metastasis is a complex multi-step process. When leaving the primary tumor and moving in and out of blood vessels, cancer cells must initially break through the extracellular matrix and basement membrane barrier to infiltrate the adjacent fibrous connective tissue before moving to more distant sites (41). The degradation of the extracellular matrix and the basement membrane is generally conductedby MMPs, hyaluronidase, elastase, cathepsin and large numbers of macrophages (42). MMPs are proteolytic enzymes that are closely associated with tumor invasion and metastasis (43). 
They are directly involved in tissue damage, induce VEGF and stimulate endothelial cells to synthesize proteases that lead to endothelial cell proliferation and migration (44). MMPs are considered to be important inducers and regulators of angiogenesis (45). MMP9 is a type IV collagenase that acts as a protease in tumor invasion and metastasis primarily by degrading collagen type III and IV in the extracellular matrix and the basement membrane of blood vessel walls (46). MMP9 is also involved in the formation of blood vessels in tumors (47). The increased expression of MMP9 is associated with tumor malignancy and prognosis $(48,49)$ and it has been demonstrated that disease-free and 5-year survival rates are significantly decreased in patients with gliomas that are MMP9 positive compared with those that are MMP9 negative. In the present study, the results of RT-qPCR and western blotting demonstrated that the expression of MMP9 in DcR3-knockdown HepG2 cells treated with FasL was significantly lower than in normal and FasL-treated normal HepG2 cells, indicating that FasL may reduce the expression of MMP9 and inhibit tumor angiogenesis invasion and metastasis in HepG2 cells following DcR3 silencing.

There have been few studies investigating tumor lymphangiogenesis; attention has focused on angiogenesis, due to its importance during the tumorigenesis of solid tumors (50-52). In fact, due to their structure and function, lymphatic vessels are not only involved in maintaining tumor growth, but are also the major cause of metastasis indifferent types of cancer and are key factors determining cancer stage and patient prognosis (53). Lymph node metastasis is commonly used as a guide for treatment selection (54). The liver is an organ containing abundant blood vessels and liver cancer tissues exhibit a large amount of lymphangiogenesis that is closely associated with liver cancer cell migration and invasion (55).

Tumor lymphangiogenesis is extremely complex. Tumor cells, stromal cells, macrophages and activated platelets all can secrete a variety of lymphatic growth factors that induce the formation of new tumor lymphatic vessels and promote tumor lymphatic metastasis (56). The dimeric glycoproteins VEGF-C and VEGF-D, are the most well-studied lymphatic endothelial growth factors. VEGF-C was the first lymphatic endothelial growth factor identified to serve a role in promoting lymphangiogenesis (57). VEGF-D was identified in 1998 and was determined to have a similar structure, function and common specific receptor to VEGF-C (58). It has been demonstrated that VEGF receptor 3 (VEGFR3) has the highest affinity in binding to VEGF-C/D (59). VEGFR3 is primarily expressed in embryonic and adult lymphatic endothelial cells and is an important signal that mediates lymphangiogenesis. Following the binding of VEGFR-3 to VEGF-C/D, lymphatic endothelial cell proliferation and migration is stimulated, tumor lymphangiogenesis is promoted, tumor cells move into lymphatic vessels and cancer metastasis occurs via the lymphatic system (60-62). It has been demonstrated that VEGF-C exhibits the strongest promoting effect on lymphangiogenesis (63). It is highly expressed in lung, breast, stomach and colon cancer tumors and is closely associated with tumor lymphoid metastasis (64). Tumor cells are able to secrete large amount of growth factors to promote angiogenesis, providing essential nutrients to the tumor tissue, promoting tumor lymphangiogenesis and mediating tumor invasion. It has been reported that tumor angiogenesis is associated with VEGF-A/VEGFR-2 and that lymphangiogenesis is primarily regulated by VEGF-C, VEGF-D and VEGFR-3 (65). Under normal physiological conditions, VEGF-C and VEGF-D are able to mediate endothelial cell mitosis, cell migration and apoptosis (66). However, when cells are in abnormal states of proliferation and activation (i.e., tumorigenesis), tumor cells stimulate the surrounding tissues and induce lymphangiogenesis via autocrine and paracrine signaling. Growth of the newly formed lymphatic vessels is promoted, as is tumor lymphatic metastasis (67). The results of the current study demonstrated that the expression of VEGF-C and VEGF-D in DcR3-silenced cells following treatment with FasL was significantly decreased compared with normal and FasL-treated normal cells, indicating that FasL reduces the expression of VEGF-C and VEGF-D following the downregulation of DcR3 in vitro, thus impairing the ability of lymphangiogenesis and lymph node metastasis of HepG2 cells.

In conclusion, the results of the current study indicate that FasL increases the apoptosis of HepG2 cells and significantly decreases the proliferation and invasion of HepG2 cells following DcR3 silencing. This may be due to the downregulation of MMP9, VEGF-C, VEGF-Dexpression; however, its exact mechanism of action remains unclear and further studies are required. The results of the present study suggest that DcR3 silencing combined with FasL treatment may be a novel method of treating patients with liver cancer, particularly those with hepatoblastoma.

\section{Acknowledgements}

Not applicable.

\section{Funding}

The present study was funded by the National Natural Science Foundation of China (Grant no. 81550033).

\section{Availability of data and materials}

The datasets used and/or analyzed during the current study are available from the corresponding author on reasonable request.

\section{Authors' contributions}

TZ designed the study, performed experiments, analyzed the data and wrote the paper. YX, SR and XZ performed experiments. CL analyzed data. JW initiated, organized and designed the study, and wrote the paper

\section{Ethics approval and consent to participate}

Not applicable.

\section{Consent for publication}

Not applicable.

\section{Competing interests}

The authors declare that they have no competing interests. 


\section{References}

1. Ferlay J, Soerjomataram I, Dikshit R, Eser S, Mathers C, Rebelo M, Parkin DM, Forman D and Bray F: Cancer incidence and mortality worldwide: Sources, methods and major patterns in GLOBOCAN 2012. Int J Cancer 136: E359-E386, 2015.

2. Altekruse S, McGlynn K and Reichman M: Hepatocellular carcinoma incidence, mortality, and survival trends in the United States from 1975 to 2005. J Clin Oncol 27: 1485-1491, 2009.

3. Forner A, Llovet J and Bruix J: Hepatocellular carcinoma. Lancet 379: 1245-1255, 2012.

4. Xu X, Chen W, Miao R, Zhou YY, Wang ZX, Zhang LQ, Qu K, Pang Q, Wang RT and Liu C: Survival analysis of hepatocellular carcinoma: A comparison between young patients and aged patients. Chin Med J (Engl) 128: 1793-1800, 2015.

5. Darbari A, Sabin KM, Shapiro CN and Schwarz KB: Epidemiology of primary hepatic malignancies in U.S. children. Hepatology 38: 560-566, 2003.

6. Meyers RL, Rowland JR, Krailo M, Chen Z, Katzenstein HM and Malogolowkin MH: Predictive power of pretreatment prognostic factors in children with hepatoblastoma: A report from the Children's Oncology Group. Pediatr Blood Cancer 53: 1016-1022, 2009.

7. Watanabe K: Current chemotherapeutic approaches for hepatoblastoma. Int J Clin Oncol 18: 955-961, 2013.

8. Zsiros J, Brugieres L, Brock P, Roebuck D, Maibach R, Zimmermann A, Childs M, Pariente D, Laithier V, Otte JB, et al: Dose-dense cisplatin-based chemotherapy and surgery for children with high-risk hepatoblastoma (SIOPEL-4): A prospective, single-arm, feasibility study. Lancet Oncol 14: 834-842, 2013.

9. Bell D, Ranganathan S, Tao J and Monga SP: Novel advances in understanding of molecular pathogenesis of hepatoblastoma: A Wnt/ $\beta$-catenin perspective. Gene Expr 17: 141-154, 2017.

10. Ganju A, Khan S, Hafeez BB, Behrman SW, Yallapu MM, Chauhan SC and Jaggi M: miRNA nanotherapeutics for cancer. Drug Discov Today 22: 424-432, 2017.

11. Wang Z, Wang N, Liu P and Xie X: AMPK and cancer. EXS 107: 203-226, 2016.

12. De la Rosa AJ, Gomez MA, Morales S, Padillo FJ and Muntane J: CD95 signaling in cancer treatment. Curr Pharm Des 20: 2809-2818, 2014.

13. Ogasawara J, Watanabe-Fukunaga R, Adachi M, Matsuzawa A, Kasugai T, Kitamura Y, Itoh N, Suda T and Nagata S: Lethal effect of the anti-Fas antibody in mice. Nature 364: 806-809, 1993.

14. Suda T, Takahashi T, Golstein P and Nagata S: Molecular cloning and expression of the Fas ligand, a novel member of the tumor necrosis factor family. Cell 75: 1169-1178, 1993.

15. Mor G, Gutierrez L, Eliza M, Kahyaoglu F and Arici A: Fas-fas ligand system-induced apoptosis in human placenta and gestational trophoblastic disease. Am J Reprod Immunol 40: 89-94, 1998.

16. Müschen M, Warskulat U and Beckmann M: Defining CD95 as a tumor suppressor gene. J Mol Med (Berl) 78: 312-325, 2000.

17. Kim SK, Yoon YD, Park YS, Seo JT and Kim JH: Involvement of the Fas-Fas ligand system and active caspase-3 in abnormal apoptosis in human testes with maturation arrest and Sertoli cell-only syndrome. Fertil Steril 87: 547-553, 2007.

18. Lau HT, Yu M, Fontana A and Stoeckert C Jr: Prevention of islet allograft rejection with engineered myoblasts expressing FasL in mice. Science 273: 109-112, 1996.

19. Pitti RM, Marsters SA, Lawrence DA, Roy M, Kischkel FC, Dowd P, Huang A, Donahue CJ, Sherwood SW, Baldwin DT, et al: Genomic amplification of a decoy receptor for Fas ligand in lung and colon cancer. Nature 396: 699-703, 1998

20. Liu YQ, Mu ZQ, You S, Tashiro S, Onodera S and Ikejima T: Fas/FasL signaling allows extracelluar-signal regulated kinase to regulate cytochrome $\mathrm{c}$ release in oridonin-induced apoptotic U937 cells. Biol Pharm Bull 29: 1873-1879, 2006.

21. Connolly K, Cho YH, Duan R, Fikes J, Gregorio T, LaFleur DW, Okoye Z, Salcedo TW, Santiago G, Ullrich S, et al: In vivo inhibition of Fas ligand-mediated killing by TR6, a Fas ligand decoy receptor. J Pharmacol Exp Ther 298: 25-33, 2001.

22. Ge Z, Sanders AJ, Ye L and Jiang WG: Aberrant expression and function of death receptor-3 and death decoy receptor-3 in human cancer. Exp Ther Med 2: 167-172, 2011.

23. Wu Y, Han B, Sheng H, Lin M, Moore PA, Zhang J and Wu J: Clinical significance of detecting elevated serum DcR3/TR6/M68 in malignant tumor patients. Int J Cancer 105: 724-732, 2003.
24. Shen HW, Gao SL, Wu YL and Peng SY: Overexpression of decoy receptor 3 in hepatocellular carcinoma and its association with resistance to Fas ligand-mediated apoptosis. World J Gastroenterol 11: 5926-5930, 2005.

25. Chen $G$ and Luo D: Expression of decoy receptor 3 in liver tissue microarrays. Nat Med J India 21: 275-278, 2008.

26. Yu W, Xu YC, Tao Y, He P, Li Y, Wu T, Zhu YP, Li J, Wu JX and Dai J: DcR3 regulates the growth and metastatic potential of SW480 colon cancer cells. Oncol Rep 30: 2741-2748, 2013.

27. Zhou XN, Li GM, Xu YC, Zhao TJ and Wu JX: Knockdown of decoy receptor 3 impairs growth and invasiveness of hepatocellular carcinoma cell line of HepG2. Chin Med J (Engl) 129: 2623-2629, 2016.

28. Aden DP, Fogel A, Plotkin S, Damjanov I and Knowles BB: Controlled synthesis of HBsAg in a differentiated human liver carcinoma-derived cell line. Nature 282: 615-616, 1979.

29. López-Terrada D, Cheung SW, Finegold MJ and Knowles BB: Hep G2 is a hepatoblastoma-derived cell line. Hum Pathol 40: 1512-1515, 2009.

30. Livak KJ and Schmittgen TD: Analysis of relative gene expression data using real-time quantitative PCR and the 2(-Delta Delta C(T)) method. Methods 25: 402-408, 2001.

31. Strasser A, Jost PJ and Nagata S: The many roles of FAS receptor signaling in the immune system. Immunity 30: 180-192, 2009.

32. Chen L, Park SM, Tumanov AV, Hau A, Sawada K, Feig C, Turner JR, Fu YX, Romero IL, Lengyel E and Peter ME: CD95 promotes tumour growth. Nature 465: 492-496, 2010.

33. Barnhart BC, Legembre P, Pietras E, Bubici C, Franzoso G and Peter ME: CD95 ligand induces motility and invasiveness of apoptosis-resistant tumor cells. EMBO J 23: 3175-3185, 2004.

34. O' Reilly LA, Tai L, Lee L, Kruse EA, Grabow S, Fairlie WD, Haynes NM, Tarlinton DM, Zhang JG, Belz GT, et al: Membrane-bound Fas ligand only is essential for Fas-induced apoptosis. Nature 461: 659-663, 2009.

35. Wisniewski P, Ellert-Miklaszewska A, Kwiatkowska A and Kaminska B: Non-apoptotic Fas signaling regulates invasiveness of glioma cells and modulates MMP-2 activity via NFkappaB-TIMP-2 pathway. Cell Signal 22: 212-220, 2010.

36. Macher-Goeppinger S, Aulmann S, Wagener N, Funke B, Tagscherer KE, Haferkamp A, Hohenfellner M, Kim S, Autschbach F, Schirmacher P and Roth W: Decoy receptor 3 is a prognostic factor in renal cell cancer. Neoplasia 10: 1049-1056, 2008.

37. Connor JP and Felder M: Ascites from epithelial ovarian cancer contain high levels of functional decoy receptor 3 (DcR3) and is associated with platinum resistance. Gynecol Oncol 111: 330-335, 2008.

38. Maeda T, Hao C and Tron VA: Ultraviolet light (UV) regulation of the TNF family decoy receptors DcR2 and DcR3 in human keratinocytes. J Cutan Med Surg 5: 294-298, 2001.

39. Hayashi S, Miura Y, Nishiyama T, Mitani M, Tateishi K, Sakai Y, Hashiramoto A, Kurosaka M, Shiozawa S and Doita M: Decoy receptor 3 expressed in rheumatoid synovial fibroblasts protects the cells against fas-induced apoptosis. Arthritis Rheum 56: 1067-1075, 2007.

40. Li W, Zhang C, Chen C and Zhuang G: Correlation between expression of DcR3 on tumor cells and sensitivity to FasL. Cell Mol Immunol 4: 455-460, 2007.

41. Clark AG and Vignjevic DM: Modes of cancer cell invasion and the role of the microenvironment. Curr Opin Cell Biol 36: 13-22, 2015.

42. Laurenzana A, Fibbi G, Margheri F, Biagioni A, Luciani C, Del Rosso $\mathrm{M}$ and Chillà $\mathrm{A}$ : Endothelial progenitor cells in sprouting angiogenesis: Proteases pave the way. Curr Mol Med 15: 606-620, 2015

43. Jacob A and Prekeris R: The regulation of MMP targeting to invadopodia during cancer metastasis. Front Cell Dev Biol 3: 4, 2015.

44. Kessenbrock K, Wang CY and Werb Z: Matrix metalloproteinases in stem cell regulation and cancer. Matrix Biol 44-46: 184-190, 2015.

45. DeClerck YA, Mercurio AM, Stack MS, Chapman HA, Zutter MM, Muschel RJ, Raz A, Matrisian LM, Sloane BF, Noel A, et al: Proteases, extracellular matrix, and cancer: A workshop of the path B study section. Am J Pathol 164: 1131-1139, 2004.

46. Banday MZ, Sameer AS, Mir AH, Mokhdomi TA, Chowdri NA and Haq E: Matrix metalloproteinase (MMP) -2, -7 and -9 promoter polymorphisms in colorectal cancer in ethnic Kashmiri population-A case-control study and a mini review. Gene 589: 81-89, 2016. 
47. Verma S, Kesh K, Gupta A and Swarnakar S: An overview of matrix metalloproteinase 9 polymorphism and gastric cancer risk. Asian Pac J Cancer Prev 16: 7393-7400, 2015.

48. Komatsu K, Nakanishi Y, Nemoto N, Hori T, Sawada T and Kobayashi M: Expression and quantitative analysis of matrix metalloproteinase-2 and-9 in human gliomas. Brain Tumor Pathol 21: 105-112, 2004.

49. Visse R and Nagase H: Matrix metalloproteinases and tissue inhibitors of metalloproteinases: Structure, function, and biochemistry. Circ Res 92: 827-839, 2003.

50. Ji RC: Lymph nodes and cancer metastasis: New perspectives on the role of intranodal lymphatic sinuses. Int J Mol Sci 18: E51, 2016.

51. Paduch R: The role of lymphangiogenesis and angiogenesis in tumor metastasis. Cell Oncol (Dordr) 39: 397-410, 2016.

52. Dieterich LC and Detmar M: Tumor lymphangiogenesis and new drug development. Adv Drug Deliv Rev 99: 148-160, 2016.

53. Fink DM, Steele MM and Hollingsworth MA: The lymphatic system and pancreatic cancer. Cancer Lett 381: 217-236, 2016.

54. Christiansen A and Detmar M: Lymphangiogenesis and cancer. Genes Cancer 2: 1146-1158, 2011.

55. Tanaka M and Iwakiri Y: The hepatic lymphatic vascular system: Structure, function, markers, and lymphangiogenesis. Cell Mol Gastroenterol Hepatol 2: 733-749, 2016.

56. Li S and Li Q: Cancer stem cells, lymphangiogenesis, and lymphatic metastasis. Cancer Lett 357: 438-447, 2015.

57. Stacker SA and Achen MG: Emerging roles for VEGF-D in human disease. Biomolecules 8: E1, 2018

58. Heckman CA, Holopainen T, Wirzenius M, Keskitalo S, Jeltsch M, Ylä-Herttuala S, Wedge SR, Jürgensmeier JM and Alitalo K: The tyrosine kinase inhibitor cediranib blocks ligand-induced vascular endothelial growth factor receptor-3 activity and lymphangiogenesis. Cancer Res 68: 4754-4762, 2008.

59. Wang $\mathrm{P}$ and Cheng Y: Gene expression profile of lymphatic endothelial cells. Cell Biol Int 35: 1177-1187, 2011.
60. Hu X, Xing L, Wei X, Liu X, Pang R, Qi L and Song S: Nonangiogenic function of VEGF and enhanced radiosensitivity of HeLa cells by inhibition of VEGF expression. Oncol Res 20: 93-101, 2012

61. Gadducci A, Guerrieri ME and Greco C: Tissue biomarkers as prognostic variables of cervical cancer. Crit Rev Oncol Hematol 86: 104-129, 2013.

62. Watanabe S, Kato M, Kotani I, Ryoke K and Hayashi K: Lymphatic vessel density and vascular endothelial growth factor expression in squamous cell carcinomas of lip and oral cavity: A clinicopathological analysis with immunohistochemistry using antibodies to D2-40, VEGF-C and VEGF-D. Yonago Acta Med 56: 29-37, 2013.

63. Biedka M, Makarewicz R, Kopczyńska E, Marszałek A, Goralewska A and Kardymowicz H: Angiogenesis and lymphangiogenesis as prognostic factors after therapy in patients with cervical cancer. Contemp Oncol (Pozn) 16: 6-11, 2012.

64. Wang J, Huang Y, Zhang J, Wei Y, Mahoud S, Bakheet AM, Wang L, Zhou S and Tang J: Pathway-related molecules of VEGFC/D-VEGFR3/NRP2 axis in tumor lymphangiogenesis and lymphatic metastasis. Clin Chim Acta 461: 165-171, 2016.

65. Zhang S, Yu H and Zhang L: Role of vascular endothelial growth factor receptor-3/Flt-4 in early-stage cervical cancer. Oncol Lett 1: 453-456, 2010.

66. Bernaudin JF, Kambouchner M and Lacave R: Lymphatic vascular system, development and lymph formation. Review. Rev Pneumol Clin 69: 93-101, 2013 (In French).

67. Zhu X, Er K, Mao C, Yan Q, Xu H, Zhang Y, Zhu J, Cui F, Zhao W and Shi H: miR-203 suppresses tumor growth and angiogenesis by targeting VEGFA in cervical cancer. Cell Physiol Biochem 32: 64-73, 2013.

This work is licensed under a Creative Commons Attribution-NonCommercial-NoDerivatives 4.0 International (CC BY-NC-ND 4.0) License. 